\title{
Extinction, reacquisition, and rapid forgetting of eyeblink conditioning in developing rats
}

\author{
Kevin L. Brown and John H. Freeman \\ Department of Psychology, University of lowa, lowa City, lowa 52242, USA
}

\begin{abstract}
Eyeblink conditioning is a well-established model for studying the developmental neurobiology of associative learning and memory. However, age differences in extinction and subsequent reacquisition have yet to be studied using this model. The present study examined extinction and reacquisition of eyeblink conditioning in developing rats. In Experiment 1 , post-natal day (P) 17 and 24 rats were trained to a criterion of $80 \%$ conditioned responses (CRs) using stimulation of the middle cerebellar peduncle (MCP) as a conditioned stimulus (CS). Stimulation CS-alone extinction training commenced $24 \mathrm{~h}$ later, followed by reacquisition training after the fourth extinction session. Contrary to expected results, rats trained starting on P17 showed significantly fewer CRs to stimulation CS-alone presentations relative to P24s, including fewer CRs as early as the first block of extinction session 1. Furthermore, the P17 group was slower to reacquire following extinction. Experiment 2 was run to determine the extent to which the low CR percentage observed in P17s early in extinction reflected rapid forgetting versus rapid extinction. Twenty-four hours after reaching criterion, subjects were trained in a session split into 50 stimulation CS-unconditioned stimulus paired trials followed immediately by 50 stimulation CS-alone trials. With this "immediate" extinction protocol, CR percentages during the first block of stimulation CSalone presentations were equivalent to terminal acquisition levels at both ages but extinction was more rapid in the P17 group. These findings indicate that forgetting is observed in P17 relative to P24 rats $24 \mathrm{~h}$ following acquisition. The forgetting in P17 rats has important implications for the neurobiological mechanisms of memory in the developing cerebellum.
\end{abstract}

Eyeblink conditioning has been used extensively to investigate the neural mechanisms underlying associative learning and memory. Decades of research have established that the cerebellum is essential for the acquisition and retention of eyeblink conditioning (for review, see Freeman and Steinmetz 2011). The cerebellum receives conditioned stimulus (CS) information from the pontine nuclei via the middle cerebellar peduncle (MCP) (Steinmetz et al. 1986, 1987; Steinmetz 1990), and unconditioned stimulus (US) information is transmitted to the cerebellum via climbing fiber projections from the inferior olive (McCormick et al. 1985; Mauk et al. 1986). Learning-related plasticity is driven by the convergence of sufficiently strong CS and US inputs to the cerebellum, and feedback from the cerebellum to parts of the CS and US pathways is critical for the facilitation and maintenance of the eyeblink conditioned response (CR) (Mauk and Donegan 1997; Halverson et al. 2010). The well-defined neural circuitry characterized in adult subjects provided a "roadmap" for identifying sites of developmental change that underlie the ontogeny of eyeblink conditioning (cf., Freeman 2010).

Development of the CS and US pathways between P17 and 24 contributes to the ontogenetic emergence of eyeblink conditioning (Freeman and Nicholson 2004; Freeman 2010). Eyeblink conditioning increases substantially between P17 and P24 when standard peripheral stimuli (e.g., tones, lights) are used as CSs (Stanton et al. 1992, 1998; Paczkowski et al. 1999). Development of sensory inputs to the pontine nuclei is a rate-limiting factor in the ontogeny of eyeblink conditioning using auditory CSs (Freeman and Campolattaro 2008; Ng and Freeman 2012), and bypassing these inputs by using electrical stimulation of the pontine nuclei as a CS overcomes developmental limitations observed with

Corresponding author: kevin-brown@uiowa.edu

Article is online at http://www.learnmem.org/cgi/doi/10.1101//m.036103.114. auditory (and visual) CSs (Freeman et al. 2005). Specifically, pontine stimulation yields robust CRs in P17 rats that are comparable to CRs in P24 rats. Importantly, robust CRs are evident with paired pontine stimulation CS-US training but not with unpaired presentations of the pontine stimulation CS and the US, and CRs generated with this protocol are abolished by temporary inactivation of the cerebellum. These findings indicate that robust associative learning-specific plasticity can emerge in the cerebellum by P17 if sufficient CS input is provided. Despite advances in identifying and overcoming developmental limitations underlying acquisition of eyeblink conditioning, to date there have been no studies extending these findings to age comparisons of extinction in developing rats.

Extinction involves repeated presentation of the CS alone after paired CS-US acquisition training (Pavlov 1927). CRs gradually decrease to baseline levels over the course of CS-alone extinction trials, and findings in adult subjects from a number of preparations, including Pavlovian fear and eyeblink conditioning, indicate that extinction is new, inhibitory learning rather than erasure of original learning (Napier et al. 1992; Medina et al. 2001; Bouton 2004; Robleto et al. 2004). Fear conditioning studies in developing rats have shown that extinction at P24 or 25 leads to new learning, consistent with that seen in adult studies, whereas extinction at P17 or 18 may lead to erasure of original learning (Kim and Richardson 2010a). Possible erasure of original fear learning in younger rats may be associated with developmental changes between P17-18 and P24-25 in neural circuitry and plasticity mechanisms involved in extinction learning in adults (Kim and

(C) 2014 Brown and Freeman This article is distributed exclusively by Cold Spring Harbor Laboratory Press for the first 12 months after the full-issue publication date (see http://learnmem.cshlp.org/site/misc/terms.xhtml). After 12 months, it is available under a Creative Commons License (AttributionNonCommercial 4.0 International), as described at http://creativecommons .org/licenses/by-nc/4.0/. 
Richardson 2007, 2010a, b; Langton et al. 2007; Kim et al. 2009). Eyeblink conditioning studies in adult subjects suggest that a component of the US pathway that undergoes developmental changes between P17 and 24 is essential for normal extinction learning. Medina et al. (2002) reported that pharmacological blockade of inhibitory input to the inferior olive prevents extinction of the eyeblink CR during CS-alone training following acquisition, possibly due to preventing changes in climbing fiber activity levels necessary for normal extinction. The blockade of inhibitory input to the inferior olive in the Medina et al. study may be comparable to normal conditions in P17 rats, as the number of inhibitory synapses in the inferior olive increases dramatically between P17 and 24 in rats (Nicholson and Freeman 2003a). These findings suggest that P17 pups should show less extinction of eyeblink conditioning relative to P24 pups. However, extinction could not be studied over these ages with standard peripheral stimuli since equivalent asymptotic levels of pre-extinction conditioning could not be established.

The present study represents our initial efforts to characterize age-related changes in extinction of eyeblink conditioning in developing rats. $\mathrm{P} 17$ and 24 rats were chosen for comparison due to the developmental changes in inhibitory input to the inferior olive that occur over this period (Nicholson and Freeman 2003a; Freeman 2010). Stimulation of the MCP as a CS was used to produce equivalent pre-extinction levels of conditioning in rats trained starting on P17 or 24 (Phase 1). Extinction training (Phase 2) consisting of stimulation CS-alone trials followed acquisition, and stimulation CS-US reacquisition sessions (Phase 3) were run to determine if the original memory persisted following extinction. Our hypothesis was that extinction in rat pups initially trained on P17 would proceed more slowly relative to rats initially trained on P24 due to continued development of the inhibitory cerebellar-inferior olive pathway shown to be involved in normal extinction learning of eyeblink conditioning in adult subjects.

\section{Results}

Experiment 1: extinction and reacquisition of eyeblink conditioning in developing rats using stimulation of the middle cerebellar peduncle as a CS

The purpose of Experiment 1 was to compare acquisition, extinction, and reacquisition of eyeblink conditioning in rats trained starting on P17 or P24. To achieve comparable acquisition levels across ages while avoiding potential antidromic activation of targets upstream of the pontine nuclei, electrical stimulation of the mossy fiber projections from the pontine nuclei to the cerebellum, the MCP, was used as a CS in the present study. MCP stimulation has been shown to be an effective CS for eyeblink conditioning in adult subjects (rabbits and ferrets; Steinmetz et al. 1986; Hesslow et al. 1999; Kalmbach et al. 2009). Our hypothesis was that P17 rats would exhibit resistance to extinction-that is, CR levels that remain high despite repeated presentations of the CS without US reinforcement-relative to P24 rats due to continued development of in the inhibitory cerebellar-olivary pathway essential for normal extinction in adult subjects (Medina et al. 2002). Rats in the P17 group typically began extinction training on P19, and not later than P20, when inhibitory feedback from the cerebellum to the inferior olive is continuing to mature.

\section{Electrode placement}

The subjects were 54 rats derived from 37 litters. Twenty-four rats had accurately placed electrodes and were trained starting on P17 (paired $n=10$, unpaired $n=3$ ) or P24 (paired $n=8$, unpaired $n=$ 3; see Fig. 1). One of the P17 rats in the paired condition failed to reach criterion within six acquisition sessions and was thus excluded. Data reported in Experiment 1 are from the remaining 23 rats with accurately placed electrodes. Electrodes that were partially in the MCP and partially in another region (e.g., cerebellar cortex) were classified as missed placements.

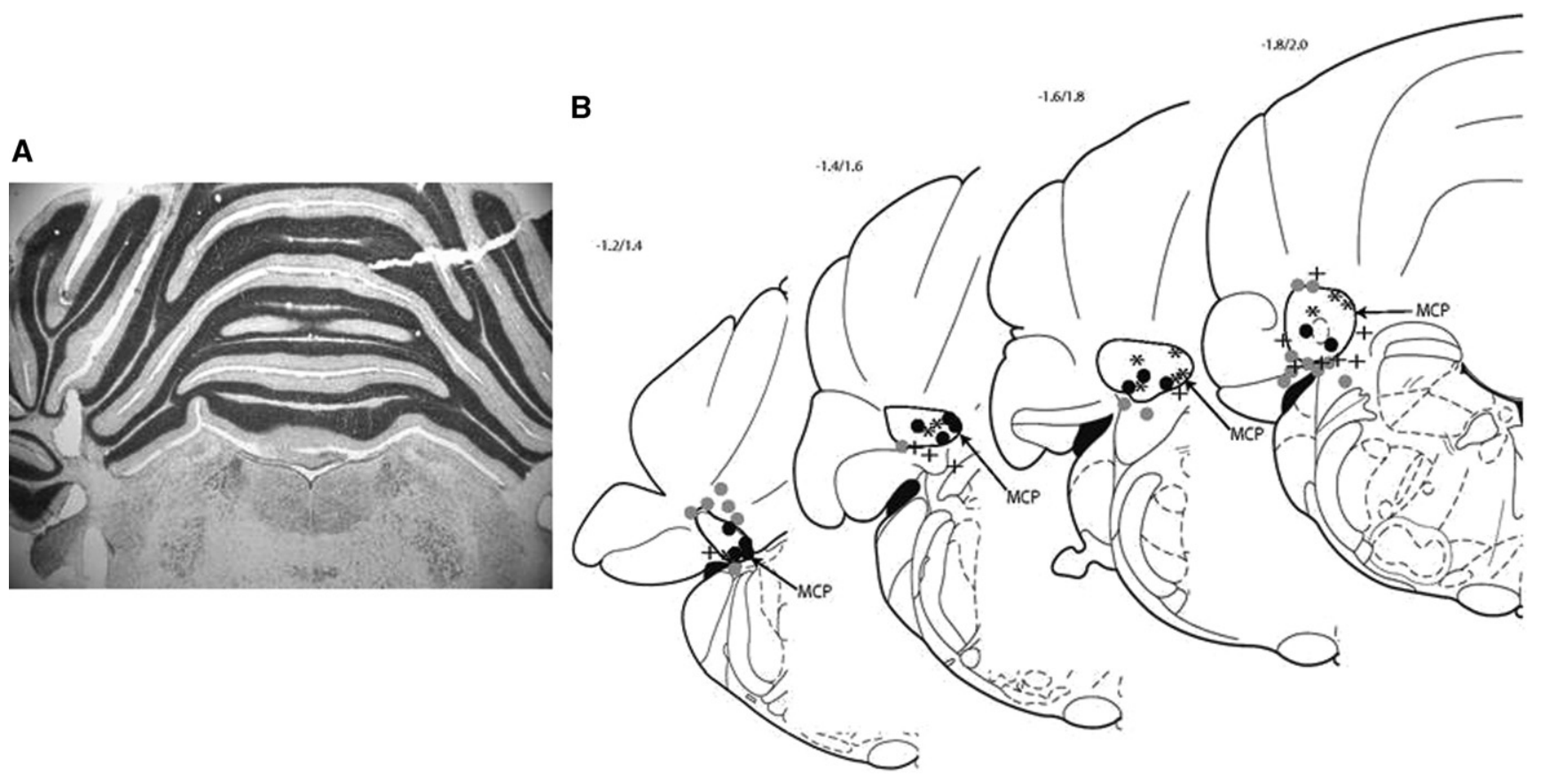

Figure 1. Stimulating electrode placements for Experiment 1. (A) Coronal section of a rat pup brain showing representative electrode placement in the middle cerebellar peduncle (MCP). (B) Electrode placement sites for all rats in Experiment 1: (black circles) P17 hit; (gray circles) P17 miss; (asterisks) P24 hit; (plus sign) P24 miss (brain sections modified from Paxinos and Watson 1998). The numbers indicate the stereotaxic coordinates in the anterior-posterior dimension relative to lambda. 


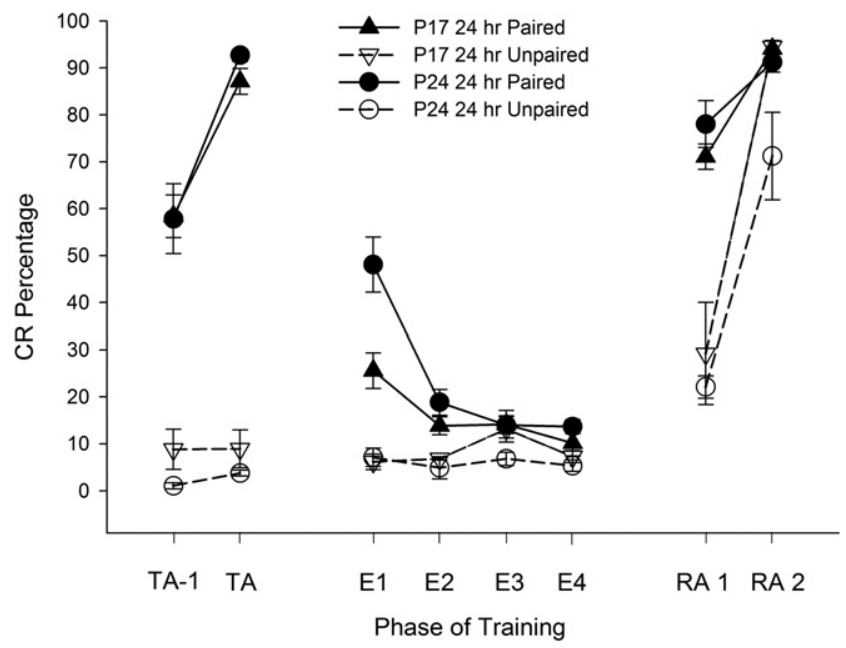

Figure 2. Mean ( \pm SEM) eyeblink conditioned response (CR) percentage for rat pups given paired (solid lines, closed symbols) or unpaired (dotted lines, open symbols) training with microstimulation of the middle cerebellar peduncle (MCP) as a conditioned stimulus (CS) starting on post-natal day (P) 17 (triangles) or 24 (circles) in Experiment 1. CR percentages are shown for the last two acquisition sessions (left side, labeled "TA", for "terminal acquisition"), extinction (four sessions, middle, labeled " $E$ "), and the first two reacquisition sessions (right side, labeled "RA").

\section{Eyeblink conditioning: acquisition}

MCP stimulation as a CS produced robust conditioning in subjects at both ages receiving paired training. Rats receiving paired presentations of MCP stimulation and the US showed a significantly higher percentage of CRs compared with rats receiving unpaired training during the last two acquisition sessions (labeled as TA-1 and TA, standing for the second to last acquisition session and the terminal acquisition session, respectively, Fig. 2, left panel). A repeated-measures ANOVA on the CR percentage data for the last two acquisition sessions revealed a significant main effect of task, $F_{(1,19)}=267.124, P<0.001$, which was due to a higher percentage of CRs in the paired groups relative to the unpaired groups. A significant interaction of Task $\times$ Session, $F_{(1,19)}=15.423, P=$ 0.001 was also found, with post hoc tests confirming that rats receiving paired training showed a significantly higher percentage of CRs during the last acquisition session relative to the penultimate acquisition session. Note that since rats were not trained with a fixed number of sessions but were instead trained until they reached a criterion of $80 \%$ CRs, the term "terminal acquisition" is used to describe the last acquisition session. The difference between paired and unpaired group performance suggests that the
CRs in subjects receiving paired training were established primarily through associative learning and were not due to pseudoconditioning or sensitization, consistent with previous reports using stimulation of proximal portions of the CS pathway as a CS in developing rats (Freeman et al. 2005; Campolattaro and Freeman 2008).

When data of subjects receiving paired training were further analyzed, age differences in the rate of acquisition were observed. A repeated-measures ANOVA on the CR percentage data for the first two acquisition sessions revealed a significant main effect of age, $F_{(1,15)}=5.361, P=0.031$, which was due to a higher percentage of CRs in the $\mathrm{P} 24$ paired group relative to the P17 paired group. Furthermore, a univariate analysis of sessions to criterion revealed a significant main effect of age, $F_{(1,17)}=7.999, P=0.013$, which was due to fewer acquisition sessions needed to reach the criterion of $80 \%$ CRs in P24 paired rats relative to P17 paired rats (see Table 1 for age comparisons of CR, startle response [SR], and unconditioned response [UR] measures at acquisition). The number of acquisition sessions needed to reach the criterion of $80 \%$ CRs ranged from 2 to 6 for P17s and from 2 to 4 for P24s.

\section{Eyeblink conditioning: extinction}

CS-alone extinction training led to a decrease in CR levels across sessions for subjects that had received paired training at acquisition (Fig. 2, middle panel). A repeated-measures ANOVA on the CR percentage data for the four extinction sessions revealed a significant main effect of task, $F_{(1,19)}=28.94, P<0.001$, which was due to a higher percentage of CRs in the paired groups relative to the unpaired groups, as well as significant main effect of session, $F_{(1.487,28.256)}=9.338, P=0.002$ (Greenhouse-Geisser correction for sphericity), which was due to a higher percentage of CRs at the first extinction session relative to extinction sessions 2 and $4(P \mathrm{~s}<0.05)$. A significant interaction of Task $\times$ Session, $F_{(1.487,28.256)}=10.650, P=0.001$ (Greenhouse-Geisser correction for sphericity) was also found, with post hoc tests showing that subjects that had received paired training had a higher percentage of CRs over extinction sessions 1-2 relative to subjects that had received unpaired training ( $P \mathrm{~s}<0.05)$. Additionally, a significant interaction of Age $\times$ Task was found, $F_{(1,19)}=4.550, P=0.046$, with post hoc tests showing higher CR levels in P24 subjects relative to P17 subjects that had received paired training, but no significant differences across age for those that had received unpaired training. The Age $\times$ Task $\times$ Session interaction failed to reach significance $(P>0.1)$.

Further analyses for subjects in the paired groups revealed age differences in the percentage of CRs during extinction training. Contrary to expected results, the percentage of CRs was higher in P24 rats in the paired group relative to P17 rats in the paired group, as revealed by a significant main effect of age, $F_{(1,15)}=8.423$,

Table 1. Mean ( \pm SE) unconditioned response amplitude (UMA) from the first block of training, startle percentage from (1) session 1 (S1), and (2) the terminal acquisition (TA) session, number of sessions to criterion, and conditioned response (CR) percentage for sessions 1 and 2 taken from rats initially trained on post-natal day $(P) 17$ or 24 from acquisition training for Experiments 1 and 2

\begin{tabular}{|c|c|c|c|c|c|c|}
\hline & \multicolumn{3}{|c|}{ Experiment 1} & \multicolumn{3}{|c|}{ Experiment 2} \\
\hline & P17 & P24 & $P$ value & P17 & P24 & $P$ value \\
\hline 1st Block UMA & $2.29( \pm 0.56)$ & $1.73( \pm 0.27)$ & 0.398 & $2.41( \pm 0.51)$ & $3.09( \pm 0.60)$ & 0.403 \\
\hline Startle Percentage (S1) & $3.26( \pm 1.30)$ & $2.81( \pm 1.00)$ & 0.793 & $5.57( \pm 1.84)$ & $3.03( \pm 1.40)$ & 0.291 \\
\hline Startle Percentage (TA) & $8.27( \pm 3.52)$ & $6.98( \pm 1.58)$ & 0.752 & $9.47( \pm 3.95)$ & $11.67( \pm 2.95)$ & 0.663 \\
\hline Sessions to criterion & $4.22( \pm 0.49)$ & $2.50( \pm 0.33)$ & 0.013 & $3.50( \pm 0.33)$ & $2.38( \pm 0.18)$ & 0.010 \\
\hline Session 1 CR Percentage & $20.62( \pm 4.04)$ & $39.91( \pm 10.31)$ & 0.089 & $36.96( \pm 8.63)$ & $42.43( \pm 7.08)$ & 0.632 \\
\hline Session 2 CR Percentage & $44.29( \pm 8.49)$ & $77.71( \pm 10.33)$ & 0.024 & $64.11( \pm 4.96)$ & $84.53( \pm 5.25)$ & 0.013 \\
\hline
\end{tabular}

$P$ values are derived from univariate analyses comparing age within each experiment, with significant differences at the 0.05 level presented in bold type. All data are from subjects receiving paired stimulation CS-US training at acquisition. 
$P=0.011$. A significant interaction of Age $\times$ Sessions was also found, $F_{(1.433,21.493)}=5.800, P=0.016$ (Greenhouse-Geisser correction for sphericity), with post hoc tests reporting a higher percentage of CRs in P24 rats relative to P17 rats at extinction session 1 . Analyses were performed on blocks of 10 trials within extinction session 1 to determine the nature of age differences early in extinction training. A significant main effect of block was found, $F_{(4.962,74.423)}=20.998, P<0.001$ (Greenhouse-Geisser correction for sphericity), and post hoc tests revealed that this was due to significantly higher CR levels during early blocks of extinction session 1 relative to later blocks $(P \mathrm{~s}<0.05)$. A significant interaction of Age $\times$ Block was also found, $F_{(4.962,74.423)}=2.952, P=$ 0.018 (Greenhouse-Geisser correction for sphericity), with post hoc tests revealing significantly higher CR percentages in P24 rats relative to $P 17$ rats over blocks $1-3$ and $7-8(P$ s $<0.05$; see Fig. 3A). The same pattern of results was observed with analyses looking at blocks of five trials at extinction session 1 (data not shown). Spontaneous recovery was assessed by comparing the last block of extinction session 1 to the first block of extinction session 2. Both P17s and P24s displayed higher CR percentages during the first block of extinction session 2 (P17 = 24\%, P24 $=33 \%$ ) compared with the last block of extinction session $1(\mathrm{P} 17=14 \%$, $\mathrm{P} 24=16 \%$ ). There was also evidence for spontaneous recovery between the end of extinction session 3 and the start of extinction session 4 (data not shown).

\section{Eyeblink conditioning: reacquisition}

Reacquisition training led to a rapid reemergence of CRs, particularly in subjects that had received paired stimulation-US training at acquisition (Fig. 2, right panel). Analyses looking at the first two sessions of reacquisition (most subjects reach the $80 \%$ criterion by the second reacquisition session) found significant main effects of task, $F_{(1,19)}=75.318, P<0.001$, and session, $F_{(1,19)}=$ 136.993, $P<0.001$, as well as significant interactive effects of Task $\times$ Session, $F_{(1,19)}=36.866, P<0.001$, and Task $\times$ Age, $F_{(1,19)}=6.497, P=0.020$. The main effects were due to higher overall CR levels in rats that had received paired training relative to rats that had received unpaired training at acquisition as well as higher overall CR levels in the second reacquisition session. The Task $\times$ Session effect was driven by significantly higher CR levels in rats that had received paired training relative to the unpaired groups at session 1 , and the Task $\times$ Age effect was driven by signifi- cantly higher CR levels during reacquisition in rats that had received unpaired training at $\mathrm{p} 17$ relative to rats that had received unpaired training at p24 (Ps $<0.05)$.

Further analyses examined reacquisition only in subjects that had received paired training at acquisition. Analyses of the first two reacquisition sessions found no significant effects as a function of training age ( $P s>0.1)$, but analyses across blocks of 10 trials within the first reacquisition session revealed a significant interaction of Age $\times$ Block, $F_{(3.874,58.115)}=3.052, P=0.025$ (GreenhouseGeisser correction for sphericity). Post hoc tests confirmed that P24 subjects that had received paired training at acquisition produced a higher percentage of CRs over the first block of reacquisition session 1 relative to $\mathrm{P} 17$ rats that had received paired training at acquisition $(P<0.05$; Fig. 3B).

\section{Eyeblink conditioning: comparisons across phases}

Additional, within-subjects comparisons were made between (1) acquisition and extinction and between (2) acquisition and reacquisition in subjects that had received paired training at acquisition. Comparisons between acquisition and extinction focused on age-related changes in measures of CR frequency, amplitude, and latency between CS-alone trials at terminal acquisition and the first 10 (CS-alone) trials at extinction session 1. One subject from each age group was excluded from this analysis due to low numbers of usable CS-alone trials. The CR percentage for rats trained at P17-but not for those trained at P24 - dropped significantly between the terminal acquisition session and the first block of extinction. This was supported by a significant interaction of Age $\times$ Phase, $F_{(1,13)}=7.741, P=0.016$, with post hoc tests confirming that the CR percentage in P17 rats at extinction block 1 was significantly lower than all other groups $(P<0.05$; Fig. 4 , top panel). Post hoc tests did not reveal significant differences between any of the other groups (P17 and 24 terminal acquisition or P24 extinction block 1). A significant main effect of age was also found, $F_{(1,13)}=7.493, P=0.017$, due to higher CR percentages in P24s relative to P17s. The same effects were observed when comparing the last 10 trials of the terminal acquisition session (nine CS+ and one CS - trial per block) with extinction block 1 (data not shown). See Table 2 for comparisons of CR amplitude, CR onset latency, and CR peak latency. Additionally, see Figure 5 for changes in CR topography as a function of age and phase of training.
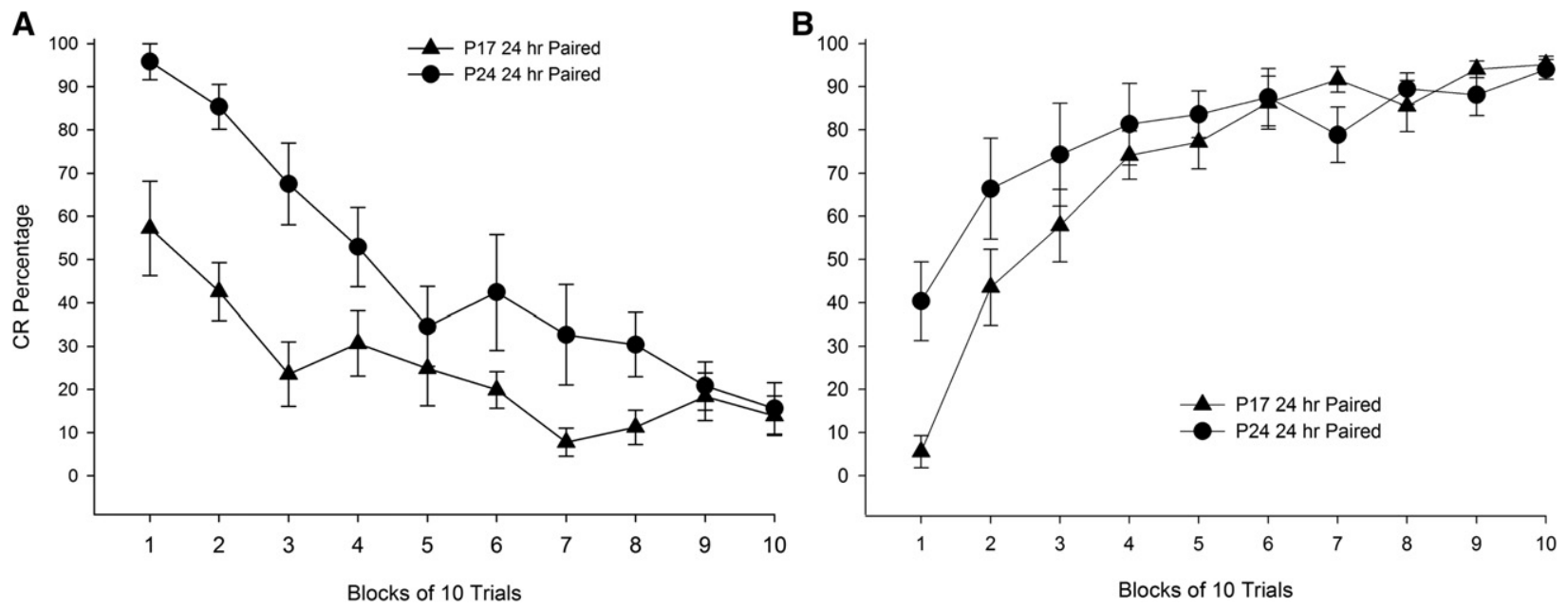

Figure 3. Mean ( \pm SEM) eyeblink conditioned response (CR) percentage during the first session of $(A)$ extinction, and $(B)$ reacquisition for rat pups given paired training with microstimulation of the middle cerebellar peduncle (MCP) as a conditioned stimulus (CS) starting on post-natal day (P) 17 (triangles) or 24 (circles) in Experiment 1. CRs are presented in blocks of 10 trials. 


\section{Terminal Acquisition}

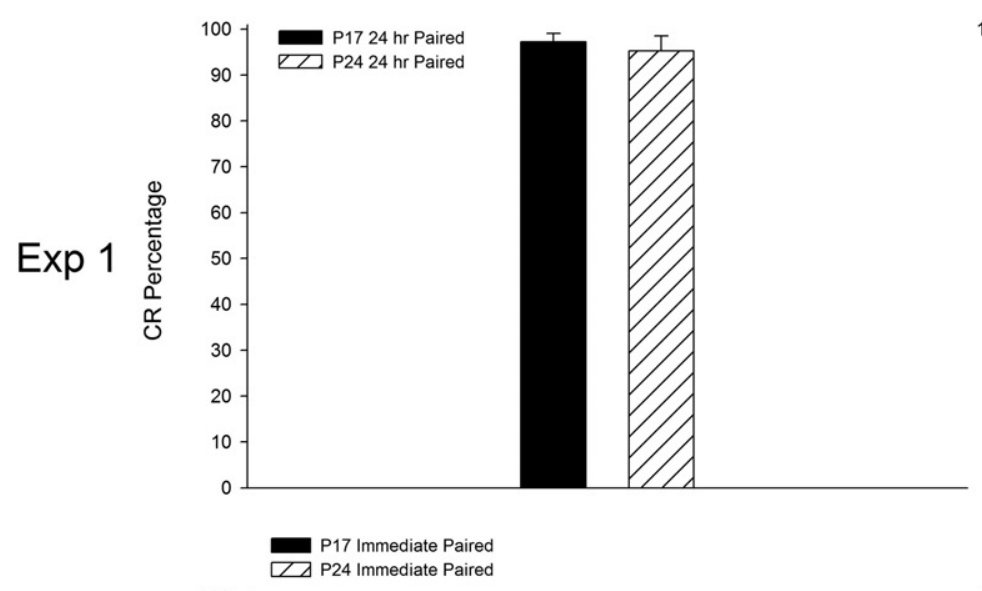

Extinction Block 1

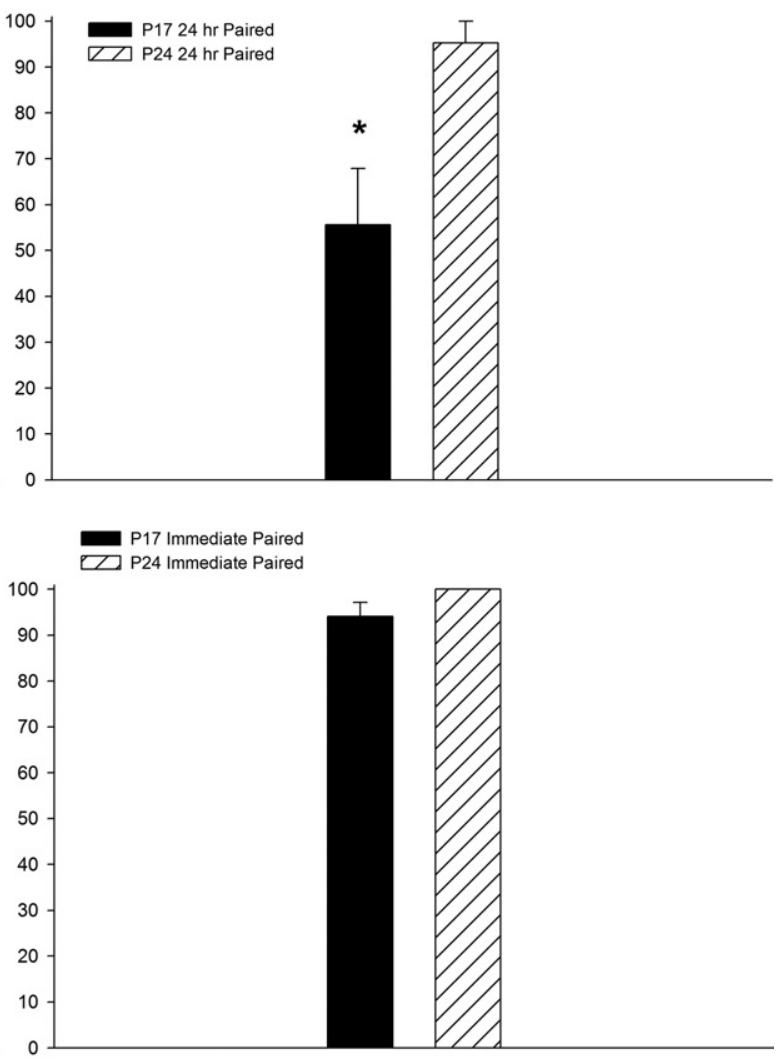

Figure 4. Mean $( \pm S E M)$ eyeblink conditioned response $(C R)$ percentage for rat pups trained with microstimulation of the middle cerebellar peduncle (MCP) as a conditioned stimulus (CS) starting on post-natal day (P) 17 (dark bars) or 24 (striped bars) in Experiment 1 (top row) or Experiment 2 (bottom row). Data are from rats that had received paired MCP-US training at acquisition. CR percentages are shown for CS-alone trials during the terminal acquisition session (left side) and the first block of 10 trials for extinction session 1 (right side). ${ }^{*}$ Denotes significant differences based on 2 (age) $\times 2$ (phase of training) ANOVAs conducted for each experiment.

Session 1 of acquisition was compared with the first reacquisition session to assess savings. If substantial savings of original learning had occurred we would expect greater CR levels at reacquisition session 1 relative to the first acquisition session. Evidence for savings was observed, as shown by a significant main effect of phase, $F_{(1,15)}=56.625, P<0.001$, due to greater $\mathrm{CR}$ percentages at reacquisition session 1 relative to the first acquisition session . The Age $\times$ Phase interaction failed to reach significance $(P>0.1)$.

\section{Experiment 1: summary}

Findings from Experiment 1 confirm that stimulation of the MCP ipsilateral to the trained eye is an effective CS for P17 and 24 rats. Rats at both ages receiving paired-but not unpaired-presentations of MCP stimulation and the US exhibited robust CRs. The rate of acquisition in P24 rats receiving paired training was faster than that of P17 rats in the paired group, but terminal acquisition levels were equivalent across age. Stimulation CS-alone extinction training led to a rapid decrease in CR levels in subjects receiving

Table 2. Mean ( \pm SE) conditioned response (CR) amplitude (arbitrary EMG units), CR onset, and CR peak latencies (in milliseconds, from CS onset) in rats initially given paired training on post-natal day $(P) 17$ or 24

\begin{tabular}{|c|c|c|c|c|c|c|}
\hline & & \multicolumn{2}{|c|}{ Experiment 1} & & \multicolumn{2}{|c|}{ Experiment 2} \\
\hline & & TA & Ext B1 & & TA & Ext B1 \\
\hline \multirow[t]{2}{*}{ CR amplitude } & P17 & $1.61( \pm 0.19)$ & $*+1.04( \pm 0.09)$ & P17 & $+1.19( \pm 0.18)$ & $+1.35( \pm 0.18)$ \\
\hline & P24 & $2.07( \pm 0.24)$ & $1.86( \pm 0.25)$ & P24 & $2.40( \pm 0.49)$ & $2.64( \pm 0.46)$ \\
\hline \multirow[t]{2}{*}{ CR onset latency } & P17 & $283.44( \pm 20.55)$ & $*+376.57( \pm 41.74)$ & P17 & $263.60( \pm 23.77)$ & $255.59( \pm 23.64)$ \\
\hline & P24 & $232.24( \pm 17.35)$ & $265.07( \pm 24.30)$ & P24 & $209.76( \pm 16.75)$ & $206.48( \pm 14.43)$ \\
\hline \multirow[t]{2}{*}{ CR peak latency } & P17 & $394.19( \pm 57.53)$ & $452.64( \pm 40.34)$ & P17 & $388.34( \pm 9.84)$ & $383.99( \pm 13.34)$ \\
\hline & P24 & $350.01( \pm 17.48)$ & $358.28( \pm 16.65)$ & P24 & $366.13( \pm 16.57)$ & $360.87( \pm 6.55)$ \\
\hline
\end{tabular}

Data are from the terminal acquisition (TA) and the first block of extinction (Ext B1) from Experiment 1 (24-h interval) or Experiment 2 (Immediate test). The * denotes significant within-age difference between terminal acquisition (TA) and the first block of extinction session 1 , and the + denotes significant differences across age. All data are from CS-alone trials in which a CR had occurred. 

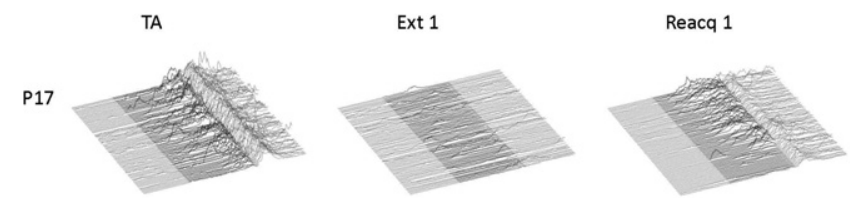

P24
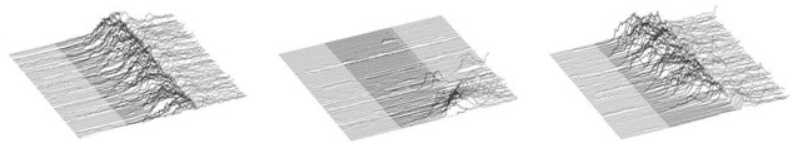

Figure 5. Example traces of eyelid EMG signals from all usable trials from terminal acquisition (TA, left), the first extinction session (Ext 1, middle), and the first reacquisition session (Reacq 1, right) from representative rats initially trained at post-natal day $(P) 17$ (top row) or P24 (bottom row) during Experiment 1 . Traces are from rats that had received paired middle cerebellar peduncle (MCP)-US training at acquisition. The shaded area indicates the MCP-CS stimulation period.

paired training at both age groups, though CR percentage levels at extinction were lower in P17s relative to P24s, contrary to expected findings. Comparisons of terminal acquisition with the first block of extinction in subjects that had received paired training at acquisition revealed a significant decrease in CR levels in P17 rats-but not in P24s-at the first block of extinction training. Findings from reacquisition training indicate substantial savings from initial learning, though reacquisition was more rapid in P24 rats receiving paired training at acquisition relative to P17 rats that had received paired training at acquisition. In contrast, P17 rats that had initially received unpaired training showed higher CR levels at reacquisition than P24 rats initially receiving unpaired training, perhaps due to learned irrelevance-like effects in the older age group (see Rush et al. 2001).

\section{Experiment 2: extinction of eyeblink conditioning in developing rats immediately following paired stimulation-US training}

The purpose of Experiment 2 was to determine the primary cause of the unexpectedly low CR levels in P17 rats during the first block of extinction session 1 in Experiment 1. Since terminal acquisition CR levels in P17s receiving paired training were robust and equivalent to those of P24s in the paired group, two explanations for the low CR levels in P17s during the first block of extinction session 1 appear likely: rapid forgetting or rapid extinction. Because of the 24-h interval between the terminal acquisition session and the first extinction session in Experiment 1, it is possible that the P17s were unable to express CRs at a similar level as terminal acquisition due to a retention deficit. Alternatively, these low CR levels may have been the result of rapid extinction perhaps related to different rates of learning between P17s and P24s. To address these possibilities, extinction was presented immediately following paired training in Experiment 2. Specifically, $24 \mathrm{~h}$ after terminal acquisition all rats received a 100-trial "immediate test" session in which the first 50 trials included CS-US presentations, just as in acquisition (paired component of immediate test), and the last 50 trials included CS-alone presentations only, just as in extinction (extinction component of immediate test). If low CR levels in P17s from Experiment 1 were primarily due to a retention deficit, then we would expect CR levels in P17s during early portions of extinction in this immediate test to remain as high as terminal acquisition levels. If, however, rapid extinction was the primary cause we would expect to see a similar decrease in CR levels in P17s during the first block of extinction relative to terminal acquisition. Our hypothesis was that CR levels during the first block of the immediate extinction test in P17s would be comparable to CR levels from terminal acquisition, thus providing evidence that the low CR levels observed early in extinction training in P17s from Experiment 1 were primarily the result of a retention deficit.

\section{Electrode placement}

The subjects were 38 rats derived from 25 litters. Seventeen rats had accurately placed electrodes, but one (P17) had a poor electromyographic (EMG) signal and was discarded. Data reported in Experiment 2 are from the remaining 16 rats with accurately placed electrodes and trained starting on P17 $(n=8)$ or P24 $(n=8)$.

\section{Eyeblink conditioning: acquisition}

As in Experiment 1, some age differences were observed in CR levels during acquisition training. Though there were no significant age differences in CR percentage during acquisition sessions 1 and $2(P>0.1)$, a univariate analysis of sessions to criterion revealed a significant main effect of age, $F_{(1,15)}=9.000, P=0.010$, which was due to fewer acquisition sessions needed to reach the criterion of $80 \%$ CRs in P24 rats relative to P17s rats (Table 1). The number of acquisition sessions needed to reach the criterion on $80 \%$ CRs ranged from 2 to 5 for P17s and from 2 to 4 for P24s. Analyses of the last two acquisition sessions did not show a significant main effect of age $(P>0.1)$, though there was a significant interaction of Age $\times$ Session, $F_{(1,14)}=7.699, P=0.015$, due to significantly higher CR levels at the penultimate acquisition session in P17 rats relative to P24 rats but higher CR levels in P24 rats relative to $\mathrm{P} 17 \mathrm{~s}$ rats at the terminal acquisition session $\left(P_{\mathrm{S}}<\right.$ 0.05; Fig. 6, left panel).

\section{Eyeblink conditioning: extinction}

Extinction training led to a significant decrease in CR levels across sessions. This was supported by a significant main effect of session, $F_{(3,42)}=111.649, P<0.001$. Age differences were also observed during extinction. This was shown by a significant main effect of

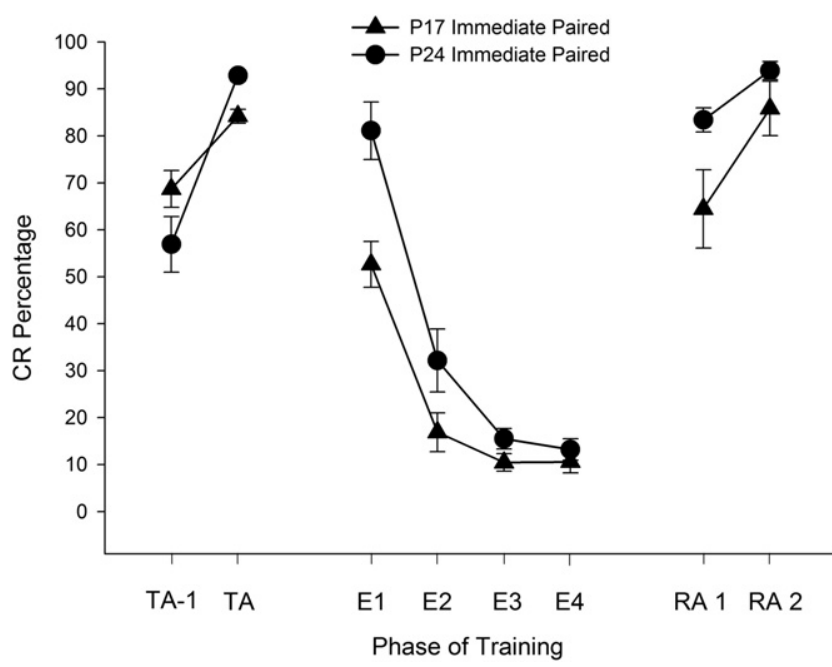

Figure 6. Mean ( \pm SEM) eyeblink conditioned response (CR) percentage for rat pups given paired training with microstimulation of the middle cerebellar peduncle (MCP) as a conditioned stimulus (CS) starting on post-natal day $(P) 17$ (triangles) or 24 (circles) in Experiment 2. CR percentages are shown for the last two acquisition sessions (left side, labeled "TA", for "terminal acquisition"), extinction (four sessions, middle, labeled " $E$ "), and the first two reacquisition sessions (right side, labeled "RA"). 
age, $F_{(1,14)}=9.393, P=0.008$, and a significant interaction of Age $\times$ Session, $\quad F_{(2.029,28.402)}=5.789, \quad P=0.008 \quad$ (GreenhouseGeisser correction for sphericity), with post hoc tests revealing significantly higher CR levels at extinction session 1 in P24 rats relative to $P 17$ rats $(P<0.05$; Fig. 6 , middle panel). As in Experiment 1 , analyses were performed on blocks of 10 trials within extinction session 1 to determine the nature of age differences early in extinction training. A significant main effect of block was found, $F_{(4,56)}=$ $35.948, P<0.001$, and post hoc tests revealed that this was due to significantly higher CR levels during early blocks of extinction session 1 relative to later blocks ( $P s<0.05)$. A significant main effect of age and a significant interaction of Age $\times$ Block was also found, $F_{(4,56)}=3.607, P=0.011$, with post hoc tests revealing significantly higher CR percentages in P24 rats relative to P17 rats over blocks $1-5$ ( $P$ s $<0.05$; see Fig. 7A for blocks of both paired [blocks 1-5] and CS-alone trials [blocks 6-10] from the immediate test). No evidence of spontaneous recovery was found between the end of extinction session 1 (block 5 ) and the start of extinction session 2 (data not shown).

\section{Eyeblink conditioning: reacquisition}

Reacquisition training led to a rapid reemergence of CRs. A main effect of session was observed, $F_{(1,14)}=23.978, P<0.001$, due to greater CR levels at reacquisition session 2 relative to reacquisition session 1, but there were no significant effects involving the factor of age. There was a trend toward significance for a main effect of age $(P=0.063$; Fig. 6 , right panel). Analyses across blocks of 10 trials within the first reacquisition session revealed a significant main effect of age, $F_{(1,14)}=4.581, P=0.050$, due to higher overall CR levels in P24s relative to P17s (Fig. 7B).

\section{Eyeblink conditioning: comparisons across phases}

Within-subjects comparisons were made between (1) acquisition and extinction and between (2) acquisition and reacquisition, as in Experiment 1. Additional comparisons across phases specific to Experiment 2 are described below. One subject from the P17 group was excluded from this analysis due to low numbers of usable CS-alone trials. Contrary to findings from Experiment 1, there were no age-related differences in the percentage of CRs between terminal acquisition and the first block of extinction $(P \mathrm{~s}>0.1$; Fig. 4, bottom panel; also see Fig. 8 for comparisons of CR topography between terminal acquisition and extinction in Experiments 1 and 2). There were also no significant effects involving age when comparing the last 10 trials of the terminal acquisition session (CS + and CS - trials) with extinction block 1 (data not shown). See Table 2 for comparisons of CR amplitude, CR onset latency, and CR peak latency. Furthermore, there were no significant age-related differences in the percentage of CRs between CS-alone trials (5) during the first 50 trials (paired component) of the immediate test and the first 5 trials of extinction (trials 51-55, Ps $>0.1$; data not shown). An additional across-phase comparison specific to Experiment 2 examined age-related differences between terminal acquisition (trials 91-100) and the first block of paired stimulation-US trials (trials 1-10 of the paired component of the immediate test) $24 \mathrm{~h}$ later. If the comparatively low CR levels in P17s at the first block of extinction session 1 from Experiment 1 ( $24 \mathrm{~h}$ after terminal acquisition) were due to partial forgetting of the stimulation CS-US training from acquisition resulting from an inability to adequately maintain the memory trace established at acquisition, then a similar low level of CRs during the first block of stimulation-CS-US trials from the paired component of the immediate test would be expected. If, however, the low CR levels at the first block of CS-alone extinction in Experiment 1 in rats receiving paired training at P17 primarily represented partial forgetting due to an inability to reach the threshold for robust CR expression, we would instead expect the high levels of CR expression present at terminal acquisition to be present at both ages with continued stimulation CS-US pairings $24 \mathrm{~h}$ later. Analyses comparing the last block of terminal acquisition and the first block of paired trials at the start of the immediate test revealed no significant effects involving the factor of age ( $P s>0.1$; data not shown). These findings suggest that learning-related plasticity established at acquisition is still present $\sim 24 \mathrm{~h}$ after paired CS-US training in rats initially trained at P17, but expression of this learning is not sufficient to consistently reach threshold for expression when tested using CS-alone trials.

Session 1 of acquisition was compared with the first reacquisition session to assess savings. Similar to findings from Experiment 1 , evidence for savings was observed based on a significant main effect of phase, $F_{(1,14)}=55.643, P<0.001$, due to greater $C R$
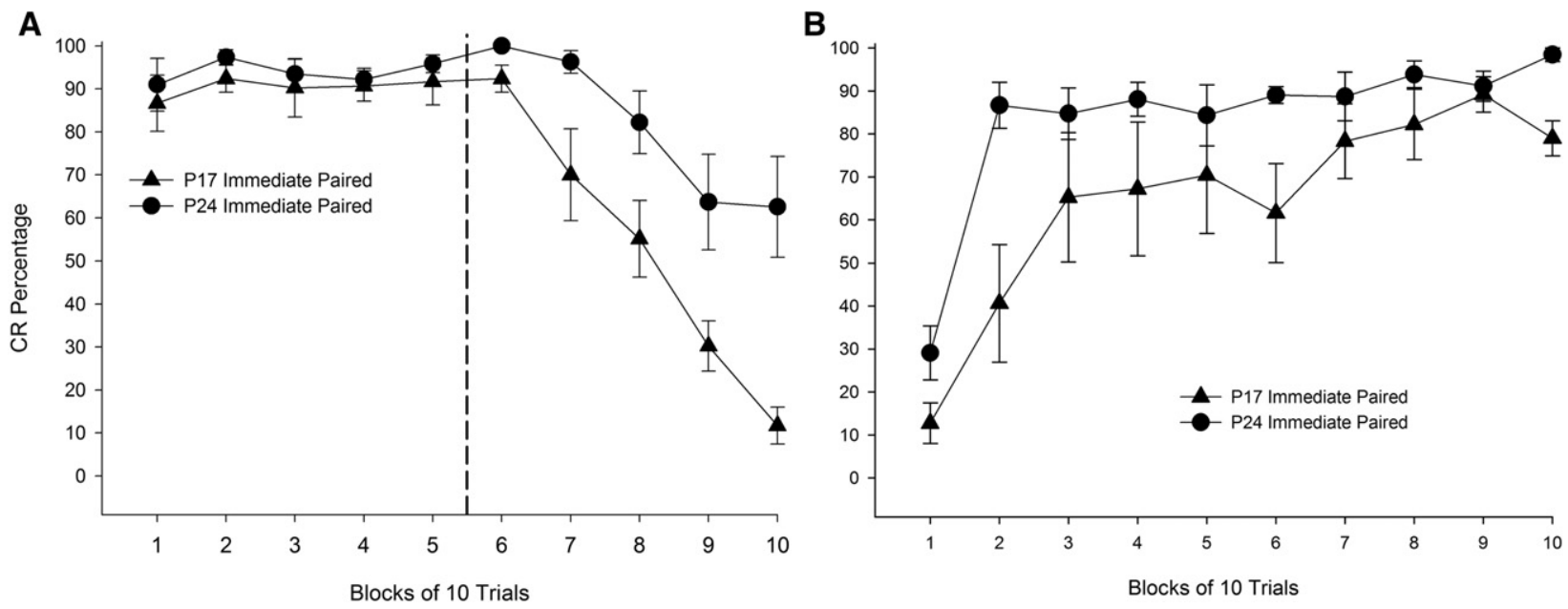

Figure 7. Mean ( \pm SEM) eyeblink conditioned response $(C R)$ percentage during the immediate test (first 50 trials $=$ conditioned stimulus $[C S]-$ unconditioned stimulus [US] paired, last 50 trials $=C S$ only extinction $(A)$, and $(B)$ first session of reacquisition for rat pups trained with microstimulation of the middle cerebellar peduncle (MCP) as a conditioned stimulus (CS) starting on post-natal day (P) 17 (triangles) or 24 (circles) in Experiment 2. Data are from rats that had received paired MCP-US training at acquisition. CRs are presented in blocks of 10 trials. The vertical dashed line between blocks 5 and 6 of the immediate test (A) represents the point at which CS-alone extinction commenced. 


\section{Terminal Acquisition}
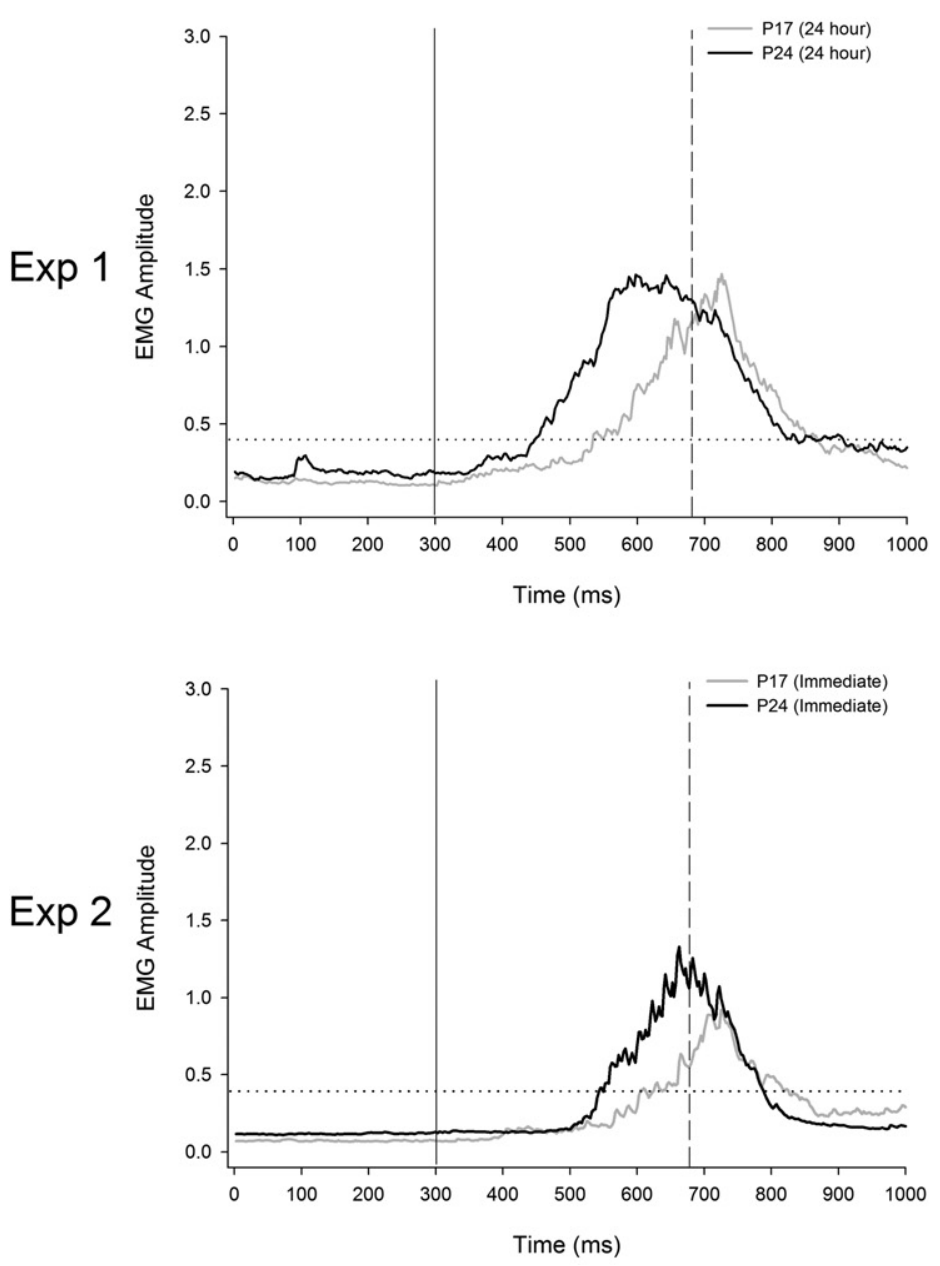

\section{Extinction Block 1}
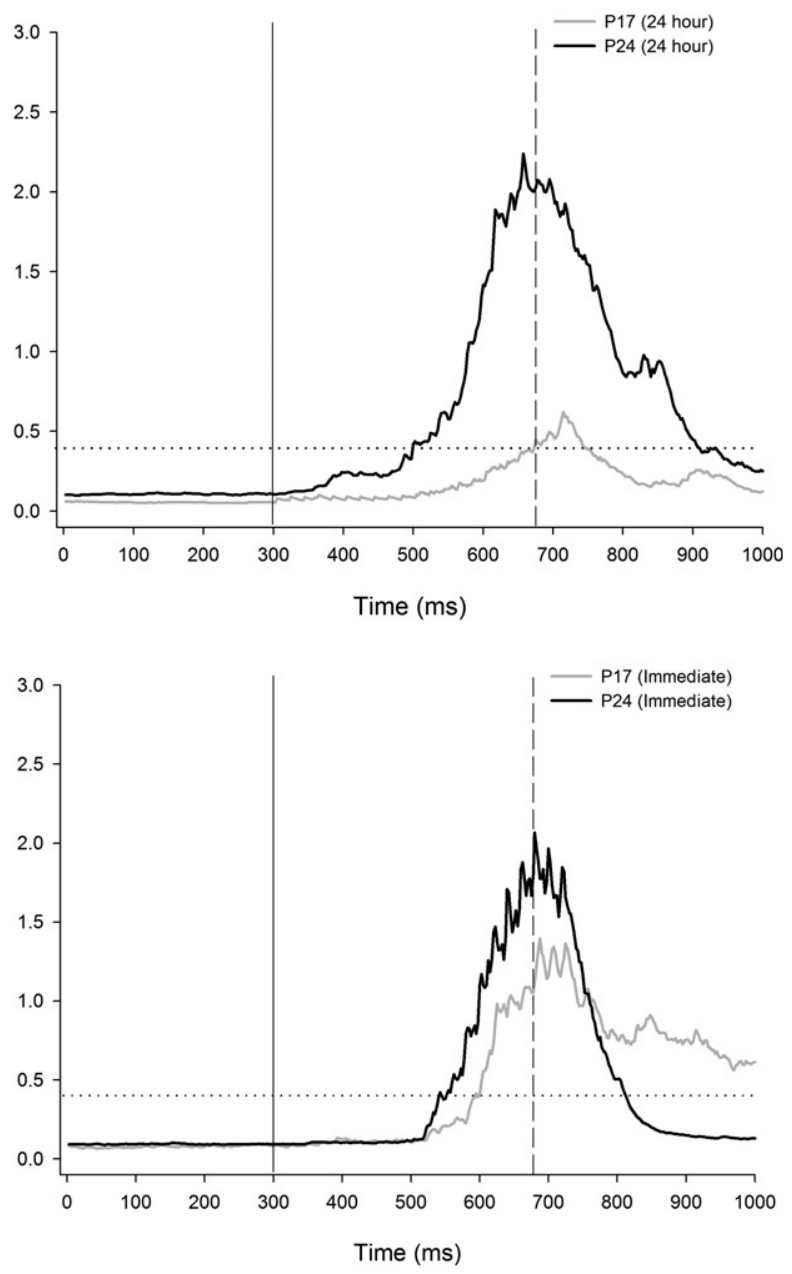

Figure 8. Mean eyelid activity during terminal acquisition (left) and the first block of extinction (right) for representative rats from Experiment 1 (top row) and Experiment 2 (bottom row). Activity from rats initially trained at post-natal day (P) 17 is depicted with gray bars and activity from rats initially trained at P24 is depicted with dark bars. Tracings are from rats that had received paired middle cerebellar peduncle (MCP)-US training at acquisition. The first vertical line (solid line) represents onset of the conditioned stimulus (CS), and the second vertical line (dashed line) represents onset of the unconditioned stimulus (US) during paired trials. The dotted horizontal line represents response threshold. Tracings represent activity during CS-alone trials.

percentages at reacquisition session 1 relative to the first acquisition session. There were no significant effects involving the factor of age (Ps $>0.1)$.

\section{Experiment 2: summary}

The overall patterns of age differences in acquisition and reacquisition reported in Experiment 1 were observed in Experiment 2. P24s reached criterion faster than P17s during acquisition, and $\mathrm{P} 24 \mathrm{~s}$ displayed a higher overall CR percentage during the first reacquisition session relative to P17s, similar to findings from Experiment 1 . Robust savings was evident at both ages as determined by comparisons between the first acquisition session and the first reacquisition session, also consistent with Experiment 1. Extinction was more rapid in $\mathrm{P} 17 \mathrm{~s}$ relative to $\mathrm{P} 24$, though within-subjects comparisons of CR percentages during the terminal acquisition session and the first block of extinction did not reveal any age-related differences, contrary to findings from Experiment 1. These findings indicate that the comparatively low CR levels at the first block of extinction in Experiment 1 in the P17 group represented a retention deficit.

\section{Discussion}

Stimulation of the MCP was an effective CS for eyeblink conditioning in rats aged P17 or 24, as seen in previous studies that used adult subjects (Steinmetz et al. 1986; Hesslow et al. 1999; Kalmbach et al. 2009). CR levels increased across acquisition sessions in groups at both ages given paired stimulation CS-US training, but not in groups receiving explicitly unpaired presentations of the stimulation CS and US. Robust conditioning in subjects receiving paired training therefore appeared to be due to associative learning rather than pseudoconditioning or sensitization, consistent with previous reports from this laboratory using stimulation of the pontine nuclei as a CS in developing rats (Freeman et al. 2005; Campolattaro and Freeman 2008). Following acquisition, extinction training (starting on either P18-20 or P25-26) consisting of presentations of the stimulation CS without the US led to a decrease in CRs at both ages, though CRs declined more rapidly in the P17 relative to the P24 group, contrary to expected findings. Furthermore, the low CR levels observed early in extinction session 1 in P17s from Experiment 1 can be partially attributed to poorer retention of paired stimulation CS-US training relative 
to P24s. Reacquisition training following extinction led to a rapid reemergence of CRs in subjects at both ages initially given paired training at acquisition. Substantial savings was evident in groups that had received paired training at acquisition at both ages as demonstrated by higher CR levels at the first reacquisition session relative to the first acquisition session, though robust CRs were evident earlier in reacquisition in P24s relative to P17s.

The present study is the first to report age-related differences in retention of eyeblink conditioning in developing rats. Expression of CRs was weaker in P17s relative to P24s $24 \mathrm{~h}$ following paired stimulation CS-US training (Experiment 1). Though P17s were slower to acquire than P24s, the demonstration in Experiment 2 of equivalent CR percentages across ages between the end of acquisition and the first block of CS-alone trials presented immediately after suggests that the low CR levels observed at the first block of extinction in P17s from Experiment 1 cannot be explained solely by poorer original learning or to more rapid extinction in P17s. These findings are therefore similar to a phenomenon known as "infantile amnesia." Infantile amnesia was initially described in humans and refers to the inability to recall experiences that occurred over the first 3-5 yr of life (for review, see Campbell and Spear 1972). Extensive systematic studies of infantile amnesia using nonhuman animals (typically mice or rats) in a variety of aversive learning paradigms have shown that younger animals forget faster than older animals (Campbell and Campbell 1962; Campbell 1967; Campbell et al. 1968; Feigley and Spear 1970; Schulenburg et al. 1971; Anderson and Riccio 2005; Akers et al. 2012, 2014; Kim et al. 2012). Consistent with the present findings, long-term retention deficits in young animals are shown even when immediate, or short-term retention is equivalent across ages, thus confirming that long-term retention deficits do not simply reflect poorer initial learning. It is important to note that the retention deficits observed $24 \mathrm{~h}$ after terminal acquisition training in P17s initially given paired stimulation CS-US training represent partial, rather than complete, forgetting. Evidence of spontaneous recovery-at both ages-between the end of extinction session 1 and the start of extinction session 2 (Experiment 1 ), for example, suggests that the memory from acquisition is retained. Furthermore, though CR levels were significantly lower in P17s during initial CS-alone presentations relative to terminal acquisition, they were significantly higher than CR levels at extinction in rats at both ages given unpaired training at acquisition. Future studies may attempt to identify intervals between terminal acquisition and retention testing that yield low CR levels in P17 paired groups comparable to those following unpaired training.

Our findings are also in agreement with prior nonhuman studies of the infantile amnesia phenomenon in that the retention deficit observed in P17s appears to reflect a failure to adequately express the memory established at acquisition (Campbell and Jaynes 1966; Silvestri et al. 1970; Spear and Parsons 1976). Studies in developing rats have demonstrated that a forgotten fear memory can be expressed by presenting reminder cues-including one US presentation (Kim and Richardson 2007) or multiple US presentations (Campbell and Jaynes) - during the interval between training and CS-alone retention testing. In eyeblink conditioning, retention is typically measured in two ways: CS-alone or CS-US tests. Retention deficits addressed thus far were observed during CS-alone tests. However, previous eyeblink studies in adult rats (Nicholson et al. 2003) and rabbits (Schreurs 1993) have reported differences in CR retention as measured during CS-alone tests and during CS-US reacquisition tests. For example, Nicholson et al. (2003) found poor retention of eyeblink CRs in adult rats following a 3-mo retention interval during CS-alone testing, though robust savings was evident following a 3-mo interval during CSUS reacquisition testing. This dissociation suggests the possibility that substantial learning-related plasticity may remain after suffi- ciently long retention intervals despite the absence of robust CR expression. In the present study, a similar dissociation was observed when comparing the first block of stimulation CS-alone trials from Experiment 1 to the first block of stimulation CS-US trials during the first half of the immediate test from Experiment 2. The presence of robust CRs during initial CS-US presentations at the "immediate test" in Experiment 2 provides compelling evidence that the poor retention in P17s observed during CS-alone testing in Experiment 1 reflected an inability to express the memory formed at acquisition training. Whether multiple paired CS-US presentations (retraining) are necessary for memory retrieval of rapidly forgotten memories in eyeblink conditioning or if reminder treatments are sufficient to retrieve poorly expressed CRs in developing rats is currently unknown. It may be useful to present a US reminder, or multiple US reminders, during the retention period in future eyeblink studies in order to facilitate comparison with previous infantile amnesia studies and to identify the conditions under which poorly expressed memories can be retrieved.

Reacquisition training (Phase 3) was included to determine the extent to which extinction affected the memory formed at acquisition. The emergence of CRs at a significantly more rapid rate during the first reacquisition session compared with the first acquisition session is taken as evidence of "savings" of the initial memory (Napier et al. 1992; Schreurs 1993; Medina et al. 2001; Nicholson et al. 2003). Reacquisition training provided the added benefit of confirming that the low CR levels observed during stimulation CS-alone extinction training were not due to damage or instability in the electrode used to deliver the stimulation CS, nor the result of tissue damage following repeated stimulations. The robust CRs observed during early blocks of reacquisition training provided evidence not only that the decline in CRs during extinction were a natural consequence of removing the US reinforcement but also that the memory established at paired acquisition training persisted after extensive CS-alone presentations. These findings of robust savings are therefore compatible with many current models of learning which propose that extinction involves new learning rather than unlearning of the memory formed at acquisition (see Bouton 2004). In contrast, Pavlovian conditioning studies using freezing as a measure of learned fear have demonstrated that extinction may cause unlearning at P17-18 but not at P24-25 (Kim and Richardson 2010a; also see Gogolla et al. 2009 , for evidence of unlearning following extinction of fear conditioning in P16 but not in P23 mice). Though savings was evident at both ages, paired P17 rats in the present study reacquired slower than their P24 counterparts. It should be noted that the slower reacquisition in the P17 paired group may have been due to extinction training, poorer retention due to the length of time between terminal acquisition and the start of reacquisition, or some combination of the two factors. It is of interest to more fully characterize what conditions, if any, yield evidence of unlearning of the original CS-US association following extinction in developmental studies of eyeblink conditioning.

MCP stimulation used in the present study served as an effective CS in developing rats, thus providing further support for our claim that the ontogenetic emergence of eyeblink conditioning is influenced by developmental changes in the CS pathway (Freeman 2010). Acquisition levels resulting from stimulation of the MCP paired with the periorbital shock US would be expected to be comparable to those seen with pontine stimulation as a CS, since the MCP comprises the axons projecting from the pontine nuclei to the cerebellum. Though MCP stimulation as a CS produced robust conditioning at both ages, acquisition rates differed somewhat from those reported in a previous study using pontine stimulation as a CS in P17 and 24 rats (Freeman et al. 2005). These differences may be accounted for by a number of factors, including possible antidromic activation of areas projecting to the 
pontine nuclei that may have been avoided by MCP stimulation in the present study. These studies also differed in the strength of the stimulation CS. Whereas a 100- $\mu$ A stimulation was used throughout in the current study, stimulation intensities in the Freeman et al. study were determined in each rat by presenting the stimulation starting at $50 \mu \mathrm{A}$ and adjusting levels in $5 \mu \mathrm{A}$ increments until a visible movement was detected. The stimulation intensity was set to half of the value that elicited movement, with average stimulation intensities of $\sim 67-74 \mu \mathrm{A}$. Differences across studies in other parameters (e.g., CS and US durations) may also contribute to differences in conditioning across studies. A recent eyeblink conditioning study from our laboratory using a somatosensory CS consisting of a mild floor vibration reported acquisition rates and CR amplitudes in rats initially trained starting on P17 or 24 comparable to those reported here (Goldsberry et al. 2014). Furthermore, CR percentages during early blocks of extinction ( $\sim 24 \mathrm{~h}$ after terminal acquisition) in P17 rats conditioned with a vibration CS (Goldsberry et al., Experiment 3) were comparable to those observed in P17s from Experiment 1. Though the complete CS pathway for a floor vibration CS has not been identified, somatosensory CS input essential for eyeblink conditioning appears to be transmitted to the cerebellum via the MCP (Lewis et al. 1987). Future developmental studies utilizing a floor vibration CS may therefore be useful to determine the generality of the age differences in CR retention, extinction, and reacquisition found in the present study.

Learning-related plasticity established in the cerebellum using aforementioned stimulation or somatosensory CSs is sufficient to support acquisition of eyeblink conditioning in preweanling rats, but the present findings indicate that the neural mechanisms underlying retention undergo continued development over P17-24. Developmental changes in the US pathway between P17 and 24 may account for rapid forgetting in P17 rats. A critical component of the US pathway is the inhibitory feedback from the cerebellar deep nuclei to the inferior olive. The inferior olive is the source of climbing fiber US inputs to the cerebellum, and inhibitory feedback from the deep nuclei to the inferior olive-including cerebellar outputs related to CR generation-is hypothesized to regulate climbing fiber activity and thus maintain learning-related plasticity in the cerebellum (Sears and Steinmetz 1991; Mauk and Donegan 1997; Kenyon et al. 1998a, b; Medina et al. 2002; Bengtsson and Hesslow 2006). There are fewer inhibitory synapses in the inferior olive in $\mathrm{P} 17$ rats relative to $\mathrm{P} 24$ rats, and, as a result of this relative lack of inhibition, learning-related Purkinje cell activity associated with inferior olive input is temporarily suppressed immediately following the US during CR trials in P24s but undergoes no CR-related modification in P17s (Nicholson and Freeman 2003a). It is therefore possible that learning-related plasticity established in P17s using MCP stimulation as a CS was unable to be expressed as well as in P24s following a 24-h retention interval due to partial dysregulation of cerebellar activity resulting from insufficient feedback from the cerebellum to the inferior olive (cf., Freeman and Nicholson 2004). This hypothesis could be tested by replicating the current procedures while simultaneously blocking inhibitory input to the inferior olive during all phases of training. Demonstration of impaired retention in P24s receiving pharmacological blockade of inhibitory inputs would provide convincing evidence in support of the hypothesis that the relative lack of inhibitory inputs to the inferior olive in P17s is the primary cause of rapid forgetting. Indeed, evoked Purkinje cell firing patterns related to inhibitory feedback of the cerebello-olivary pathway differ between P17 and P24 rats under normal conditions, but infusion of a GABA antagonist (picrotoxin) into the inferior olive results in Purkinje cell activity in P24s that resemble patterns observed in P17s under normal conditions (Nicholson and Freeman 2003b). Additionally, developmental changes in other parts of the US pathway (Freeman 2010) and/or continued development of regions shown to interact with the cerebellum to support various forms of learning and memory, including the amygdala (Ng and Freeman 2014) and/or hippocampus (see Stanton 2000) may account for the retention deficit observed in the present study.

It is worth noting that developmental changes in the inhibitory cerebello-olivary pathway were hypothesized to contribute to elevated CRs, or enhanced resistance to extinction in rats initially trained at P17. Our findings of rapid forgetting in P17s evident early in extinction are in stark contrast to this hypothesis. A potential explanation for this discrepancy is the fact that the relative lack of inhibition in the inferior olive in rats initially trained on P17 is present during both acquisition and extinction training. In the Medina et al. (2002) study, rabbits underwent acquisition training under normal conditions, and picrotoxin infusions blocking inhibitory input to the inferior olive were delivered only during extinction training. According to their model, a difference in climbing fiber activity between acquisition, under normal conditions, and extinction, when inhibitory input to the inferior olive is blocked thus disrupting climbing fiber activity, is necessary to produce resistance to CS-alone extinction training. A different pattern of results would therefore be expected if pharmacological blockade of inhibitory inputs to the inferior olive also occurred during acquisition, a potential treatment that more closely resembles natural conditions in the younger age group in the present study. As discussed in the previous paragraph, acquisition under conditions in which inhibitory inputs to the inferior olive are blocked or developmentally incomplete may contribute to poor retention following relatively short periods of time.

The present findings demonstrate that MCP stimulation is an effective CS for eyeblink conditioning in P17-24 rats. For the first time we present evidence of poorer retention of eyeblink conditioning in preweanling rats relative to post-weanling rats. Consistent with prior research investigating the infantile amnesia phenomenon in nonhuman animals, this retention deficit appears to reflect an inability in younger rats to adequately express the memory formed during acquisition. Additionally, developmental differences were found in the rate of extinction and the rate of reacquisition following extinction. The well-characterized neural circuitry underlying the ontogenetic emergence of eyeblink conditioning provides a good starting point for future studies investigating developmental differences in retention and extinction of the conditioned eyeblink response.

\section{Materials and Methods}

\section{Subjects}

The subjects were female and male Long-Evans rats born and housed in the animal colony in Spence Laboratories of Psychology at the University of Iowa. All rats had ad libitum access to food and water and were maintained on a 12/12-hr light/dark cycle, with light onset at 7 a.m. Subjects were housed in polycarbonate cages with wire lids. Cages were checked during the light cycle for births and the day of birth was designated as post-natal day (P) 0. On P1 litters were culled to eight pups-four females and four males, whenever possible. No more than one pup of each sex from a given litter was assigned to an experimental group. All subjects remained housed with their mother until P19. On P19 pups were transferred to separate cages with same-sex littermates. All procedures were approved by the Institutional Animal Care and Use Committee at the University of Iowa.

\section{Surgery}

Surgery was performed $2 \mathrm{~d}$ prior to training, on P15 or P22. While anesthetized with $1 \%-3.5 \%$ isoflurane, the rat's head was 
positioned and held securely in an infant stereotaxic apparatus and the skull surface was exposed. A bipolar stimulating electrode consisting of two insulated stainless steel wires $(50 \mu \mathrm{m})$ in a plastic connector was implanted into the left MCP. The stereotaxic coordinates for the MCP were taken from lambda (P15/22: 1.60/1.55 $\mathrm{mm}$ posterior, $3.00 / 3.10 \mathrm{~mm}$ lateral (left) to midline, and 4.75 / $4.75 \mathrm{~mm}$ ventral to the skull surface). After the stimulating electrode was secure, two differential EMG electrodes were implanted in the left upper eyelid, and a ground electrode was connected to one of two skull hooks. All three wires terminated in gold pins that were secured in a plastic connector. A bipolar stimulating electrode for delivering the shock unconditioned stimulus (US) was implanted subdermally, immediately caudal to the left eye. All implants were secured to the skull hooks with bone cement. Ketofen (5 mg/kg), an analgesic, was injected subcutaneously at the end of surgery.

\section{Conditioning apparatus}

The conditioning apparatus was identical to that used in previous reports of eyeblink conditioning in developing rats from our laboratory (see Freeman et al. 2005). The apparatus consisted of a small-animal sound attenuation chamber (BRS/LVE) with a small-animal operant chamber (BRS/LVE) contained inside. Subjects were kept in the operant chamber during conditioning. Lightweight cables with connectors for the EMG and US were connected to a commutator above the conditioning chamber, and a separate cable was connected to the bipolar electrode used for delivering MCP stimulation. Both cables were threaded through holes in the ceiling of the chambers. The electrode leads from the subject's head stage were connected to peripheral equipment and a desktop computer. Computer software controlled the delivery of stimuli and the recording of eyelid EMG activity (JSA Designs). EMG activity was recorded differentially, filtered (500$5000 \mathrm{~Hz})$, amplified $(2000$ or $5000 \times)$, and integrated (time constant $=20 \mathrm{msec}$ ). Two stimulus isolators (model number 365A; World Precision Instruments) were used for each subject. One stimulus isolator delivered the US and the other delivered the electrical stimulation that served as the conditioned stimulus (CS). A programmable stimulator (Master 8, A.M.P.I.) controlled signal input to the stimulus isolator used to deliver the stimulation CS.

\section{Middle cerebellar peduncle stimulation and conditioning procedure}

Electrical stimulation of the left MCP served as the CS, which was administered in a $50 \mathrm{~Hz}$ train of $0.1-\mathrm{msec}$ biphasic pulses for 400 msec. Stimulation intensity was fixed at $100 \mu \mathrm{A}$.

Eyeblink conditioning began on P17 or 24 and all sessions (acquisition, extinction, and reacquisition) occurred over a minimum of $5 \mathrm{~d}$, with $1-2$ daily sessions. Daily sessions were separated by $\sim 4 \mathrm{~h}$. There were three phases of conditioning: acquisition, extinction, and reacquisition. During acquisition (Phase 1) subjects received paired or explicitly unpaired training with MCP stimulation and a $25 \mathrm{msec}, 3.0-\mathrm{mA}$ (range $2.5-3.5 \mathrm{~mA}$ ) periorbital stimulation US. The paired training sessions consisted of 100 trials, each with 90 trials of the stimulation CS forward paired with the US and 10 stimulation CS-alone trials that occurred on every 10th trial. CS-alone trials were included to assess conditioned response (CR) amplitude and latency uncontaminated by the unconditioned response (UR). The interstimulus interval for paired trials was $375 \mathrm{msec}$. Trials for subjects receiving paired training were separated by a variable intertrial interval (ITI) of $\sim 30 \mathrm{sec}$. Subjects in the unpaired group received 190 trials per session, 100 stimulation CS-alone trials and 90 US-alone trials. All trials in the unpaired group were separated by an ITI of $\sim 15 \mathrm{sec}$. All other aspects of the unpaired procedure were the same as paired training. All paired subjects received acquisition training (minimum of two sessions over $1 \mathrm{~d}$, maximum of six sessions over $3 \mathrm{~d}$ ) until a criterion of $80 \%$ CRs was reached. Unpaired subjects were yoked to age-matched paired training subjects to match the number of acquisition sessions consistent across training condition.
Extinction (Phase 2) consisted of four sessions of 100 stimulation CS-alone trials. Each extinction session was identical to paired training sessions with the exception that no US trials were presented. Reacquisition (Phase 3 ) commenced $\sim 24 \mathrm{~h}$ after the last extinction session. Procedures at reacquisition were identical to paired training. All conditioning sessions occurred between 7 a.m. and 7 p.m.

\section{Data analysis}

Behavioral data were examined offline from records of EMG activity sampled every $2.5 \mathrm{msec}$ during a $1 \mathrm{sec}$ trial epoch. Each $1 \mathrm{sec}$ trial for paired subjects consisted of a 300-msec pre-CS baseline period, a $400-\mathrm{msec}$ CS period, and a $300-\mathrm{msec}$ post-CS period. Eyelid EMG activity that exceeded a threshold of 0.4 arbitrary units above the mean of the pre-CS activity was scored as a response. Responses that occurred during the first $80 \mathrm{msec}$ of the CS were scored as $\alpha$ (startle) responses. During paired CS-US trials, responses that occurred between the end of the $\alpha$ period and the onset of the US were scored as CRs. EMG activity was not recorded during the 25-msec presentation of the US to avoid stimulation artifact, so responses that occurred after the offset of the US were scored as URs. During CS-alone trials, responses that occurred between the end of the $\alpha$ period and the end of the trial epoch were scored as CRs. CR amplitude and latency were measured from CS-alone trials in which a CR occurred. CR percentage from acquisition and reacquisition is reported from both CS-US and CS-alone trials. For comparisons between acquisition and extinction CR percentage is reported from CS-alone trials only. Data were analyzed via analysis of variance (ANOVA) using SPSS statistical software. Significant effects were further analyzed with Bonferroni post hoc tests. An $\alpha$ level of 0.05 was used for all statistical tests. Behavioral data are reported combined across males and females since significant differences involving the factor of sex were infrequent and inconsistent across all dependent measures.

\section{Histology}

After completion of the experiment subjects were deeply anesthetized with an overdose of sodium pentobarbital and then transcardially perfused with PBS followed by $10 \%$ formalin. After perfusion, the brains were kept in the same $10 \%$ formalin fixative for a minimum of $24 \mathrm{~h}$. The brain was then extracted and postfixed in $30 \%$ sucrose formalin. After the brain sunk in the sucrose formalin tissue was sliced at $50 \mu \mathrm{m}$, mounted on glass slides, and stained with thionin. The electrode locations were determined by examining all sections with visible track markings.

\section{Experiment 1 methods}

The experimental design of Experiment 1 included two conditions based on acquisition training (paired or unpaired) and two age groups (P17 or P24) across the three phases of conditioning. Additional analyses examined ANOVAs only for subjects receiving paired training at acquisition. Extinction training commenced $\sim 24 \mathrm{~h}$ after the terminal acquisition session in Experiment 1 .

\section{Experiment 2 methods}

The experimental design of Experiment 2 included the same two age groups as in Experiment 1 (P17 or 24) trained across acquisition, extinction, and reacquisition. All subjects received paired training at acquisition. Immediate extinction was assessed by splitting the first session following terminal acquisition (commencing $\sim 24 \mathrm{~h}$ later, as in Experiment 1) into 50 paired CS-US trials followed immediately by 50 CS-alone extinction trials. Therefore, the four sessions of stimulation-alone extinction training for Experiment 2 consisted of 50 trials for the first session and the standard 100 trials for sessions 2-4. All other aspects of the methods were identical to those of Experiment 1. 


\section{Acknowledgments}

This work was supported by National Institutes of Health grant NS038890 awarded to J.H.F. We thank Sean Farley for technical support with Figure 5.

\section{References}

Akers KG, Arruda-Carvalho M, Josselyn SA, Frankland PW. 2012. Ontogeny of contextual fear memory formation, specificity, and persistence in mice. Learn Mem 19: 598-604.

Akers KG, Martinez-Canabal A, Restivo L, Yiu AP, De Cristofaro A, Hsiang H-L, Wheeler AL, Guskjolen A, Niibori Y, Hirotaka S, et al. 2014. Hippocampal neurogenesis regulates forgetting during adulthood and infancy. Science 344: 598-602.

Anderson MJ, Riccio DC. 2005. Ontogenetic forgetting of stimulus attributes. Learn Behav 33: 444-453.

Bengtsson F, Hesslow G. 2006. Cerebellar control of the inferior olive. Cerebellum 5: 7-14.

Bouton ME. 2004. Context and behavioral processes in extinction. Learn Mem 11: 485-494.

Campbell BA. 1967. Developmental studies of learning and motivation in infra-primate mammals. In Early behavior: Comparative and developmental approaches (ed. Stevenson HW, Hess EH, Rheingold HL), pp. 43-71. Wiley, New York.

Campbell BA, Campbell EH. 1962. Retention and extinction of learned fear in infant and adult rats. J Comp Physiol Psychol 55: 1-8.

Campbell BA, Jaynes J. 1966. Reinstatement. Psychol Rev 73: 478-480.

Campbell BA, Spear NE. 1972. Ontogeny of memory. Psychol Rev 79: $215-236$.

Campbell BA, Jaynes J, Misanin JR. 1968. Retention of a light-dark discrimination in rats of different ages. J Comp Physiol Psychol 66: 467-472.

Campolattaro MM, Freeman JH. 2008. Eyeblink conditioning in 12-day-old rats using pontine stimulation as the conditioned stimulus. Proc Natl Acad Sci 105: 8120-8123.

Feigley DA, Spear NE. 1970. Effect of age and punishment condition on long-term retention by the rat of active- and passive-avoidance learning. J Comp Physiol Psychol 73: 515-526.

Freeman JH. 2010. Developmental neurobiology of cerebellar learning. In Oxford handbook of developmental behavioral neuroscience (ed. Blumberg MS, Freeman JH, Robinson SR), pp. 546-572. Oxford University Press, New York.

Freeman JH, Campolattaro MM. 2008. Ontogenetic change in the auditory conditioned stimulus pathway for eyeblink conditioning. Learn Mem 15: $823-828$

Freeman JH, Nicholson DA. 2004. Developmental changes in the neural mechanisms of eyeblink conditioning. Behav Cogn Neurosci Rev 3: 3-13.

Freeman JH, Steinmetz AB. 2011. Neural circuitry and plasticity mechanisms underlying delay eyeblink conditioning. Learn Mem 18: 666-677.

Freeman JH, Rabinak CA, Campolattaro MM. 2005. Pontine stimulation overcomes developmental limitations in the neural mechanisms of eyeblink conditioning. Learn Mem 12: 255-259.

Gogolla N, Caroni P, Lüthi A, Herry C. 2009. Perineuronal nets protect fear memories from erasure. Science 325: 1258-1261.

Goldsberry ME, Elkin ME, Freeman JH. 2014. Sensory system development influences the ontogeny of eyeblink conditioning. Dev Psychobiol 56: $1244-1251$

Halverson HE, Lee I, Freeman JH. 2010. Associative plasticity in the medial auditory thalamus and cerebellar interpositus nucleus during eyeblink conditioning. I Neurosci 30: 8787-8796.

Hesslow G, Svensson P, Ivarsson M. 1999. Learned movements elicited by direct stimulation of mossy fiber afferents. Neuron 24: 179-185

Kalmbach BE, Ohyama T, Kreider JC, Riusech F, Mauk MD. 2009. Interactions between prefrontal cortex and cerebellum revealed by trace eyelid conditioning. Learn Mem 16: 86-95.

Kenyon GT, Medina JF, Mauk MD. 1998a. A mathematical model of the cerebellar-olivary system I: Self-regulating equilibrium of climbing fiber activity. J Comput Neurosci 5: 17-33.

Kenyon GT, Medina JF, Mauk MD. 1998b. A mathematical model of the cerebellar-olivary system II: Motor adaptation through systematic disruption of climbing fiber equilibrium. J Comput Neurosci 5: 71-90.

Kim JH, Richardson R. 2007. A developmental dissociation in reinstatement of an extinguished fear response in rats. Neurobiol Learn Mem 88: $48-57$

Kim JH, Richardson R. 2010a. New findings on extinction of conditioned fear early in development: Theoretical and political implications. Biol Psychiatry 67: 297-303.

Kim JH, Richardson R. 2010b. Extinction in preweanling rats does not involve NMDA receptors. Neurobiol Learn Mem 94: 176-182.
Kim JH, Hamlin AS, Richardson R. 2009. Fear extinction across development: The involvement of the medial prefrontal cortex as assessed by temporary inactivation and immunohistochemistry. $J$ Neurosci 29: 10802-10808.

Kim JH, Li S, Hamlin AS, McNally GP, Richardson R. 2012. Phosphorylation of mitogen-activated protein kinase in the medial prefrontal cortex and the amygdala following memory retrieval or forgetting in developing rats. Neurobiol Learn Mem 97: 59-68.

Langton JM, Kim JH, Nicholas J, Richardson R. 2007. The effect of the NMDA receptor antagonist MK-801 on the acquisition and extinction of learned fear in the developing rat. Learn Mem 14: 665-668

Lewis JL, LoTurco JJ, Solomon PR. 1987. Lesions of the middle cerebellar peduncle disrupt acquisition and retention of the rabbit's classically conditioned nictitating membrane response. Behav Neurosci 101: $151-157$.

Mauk MD, Donegan NH. 1997. A model of Pavlovian eyelid conditioning based on the synaptic organization of the cerebellum. Learn Mem 3: $130-158$

Mauk MD, Steinmetz JE, Thompson RF. 1986. Classical conditioning using stimulation of the inferior olive as the unconditioned stimulus. Proc Natl Acad Sci 83: 5349-5353.

McCormick DA, Steinmetz JE, Thompson RF. 1985. Lesions of the inferior olivary complex cause extinction of the classically conditioned eyeblink response. Brain Res 359: 120-130.

Medina JF, Garcia KS, Mauk MD. 2001. A mechanism for savings in the cerebellum. J Neurosci 21: 4081-4089.

Medina JF, Nores WL, Mauk MD. 2002. Inhibition of climbing fibers is a signal for the extinction of conditioned eyelid responses. Nature 416: $330-333$

Napier NM, Macrae M, Kehoe EJ. 1992. Rapid reacquisition in conditioning of the rabbit's nictitating membrane response. J Exp Psychol Anim Behav Process 18: 182-192.

$\mathrm{Ng}$ KH, Freeman JH. 2012. Developmental changes in medial auditory thalamic contributions to associative motor learning. J Neurosci 32: 6841-6850.

Ng KH, Freeman JH. 2014. Amygdala inactivation impairs eyeblink conditioning in developing rats. Dev Psychobiol 56: 999-1007.

Nicholson DA, Freeman JH. 2003a. Addition of inhibition in the olivocerebellar system and the ontogeny of a motor memory. Nat Neurosci 6: 532-537.

Nicholson DA, Freeman JH. 2003b. Developmental changes in evoked Purkinje cell complex spike responses. J Neurophysiol 90: 2349-2357.

Nicholson DA, Sweet JA, Freeman JH. 2003. Long-term retention of the classically conditioned eyeblink response in rats. Behav Neurosci 117: $871-875$

Paczkowski C, Ivkovich D, Stanton ME. 1999. Ontogeny of eyeblink conditioning using a visual conditional stimulus. Dev Psychobiol 35: $253-263$

Pavlov IP. 1927. Conditioned reflexes: An investigation of the physiological activity of the cerebral cortex (translated by GV Anrep). Oxford University Press, London.

Paxinos G, Watson C. 1998. The rat brain in stereotaxic coordinates, 4th ed. Academic, San Diego.

Robleto K, Poulos AM, Thompson RF. 2004. Brain mechanisms of extinction of the classically conditioned eyeblink response. Learn Mem 11: $517-524$.

Rush AN, Robinette BL, Stanton ME. 2001. Ontogenetic differences in the effects of unpaired stimulus preexposure on eyeblink conditioning in the rat. Dev Psychobiol 39: 8-18.

Schreurs BG. 1993. Long-term memory and extinction of the classically conditioned rabbit nictitating membrane response. Learn Motiv 24: 293-302.

Schulenburg CJ, Riccio DC, Stikes ER. 1971. Acquisition and retention of a passive-avoidance response as a function of age in rats. J Comp Physiol Psychol 74: $75-83$

Sears LL, Steinmetz JE. 1991. Dorsal accessory inferior olive activity diminishes during acquisition of the rabbit classically conditioned eyelid response. Brain Res 545: 114-122.

Silvestri R, Rohrbaugh MJ, Riccio DC. 1970. Conditions influencing the retention of learned fear in young rats. Dev Psychobiol 2: 389-395.

Spear NE, Parsons PJ. 1976. Analysis of reactivation treatment: Ontogenetic determinants of alleviated forgetting. In Processes of animal memory (ed. Medin DL, Roberts WA, Davis RT), pp. 135-165. Erlbaum, NJ.

Stanton ME. 2000. Multiple memory systems, development, and conditioning. Behav Brain Res 110: $25-37$.

Stanton ME, Freeman JH, Skelton RW. 1992. Eyeblink conditioning in the developing rat. Behav Neurosci 106: 657-665.

Stanton ME, Fox GD, Carter CS. 1998. Ontogeny of the conditioned eyeblink response in rats: Acquisition or expression? Neuropharmacology 37: $623-632$. 
Steinmetz JE. 1990. Classical nictitating membrane conditioning in rabbits with varying interstimulus intervals and direct activation of cerebellar mossy fibers as the CS. Behav Brain Res 38: 97-108.

Steinmetz JE, Rosen DJ, Chapman PF, Lavond DG, Thompson RF. 1986. Classical conditioning of the rabbit eyelid response with a mossy-fiber stimulation CS: I pontine nuclei and middle cerebellar peduncle stimulation. Behav Neurosci 100: 878-887.
Steinmetz JE, Logan CG, Rosen DJ, Thompson JK, Lavond DG, Thompson RF. 1987. Initial localization of the acoustic conditioned stimulus projection system to the cerebellum essential for classical eyelid conditioning. Proc Natl Acad Sci 84: 3531-3535.

Received June 16, 2014; accepted in revised form August 19, 2014. 


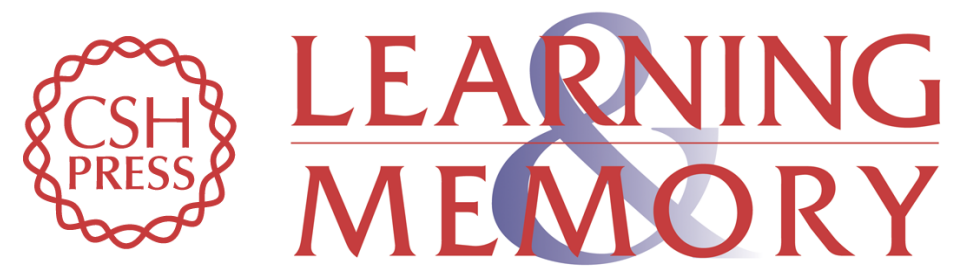

\title{
Extinction, reacquisition, and rapid forgetting of eyeblink conditioning in developing rats
}

\author{
Kevin L. Brown and John H. Freeman
}

Learn. Mem. 2014, 21:

Access the most recent version at doi:10.1101//m.036103.114

\begin{aligned} & \hline References $\begin{array}{l}\text { This article cites } 53 \text { articles, } 17 \text { of which can be accessed free at: } \\ \text { http://learnmem.cshlp.org/content/21/12/696.full.html\#ref-list-1 }\end{array} \\ & \begin{array}{r}\text { Creative } \\ \text { Commons } \\ \text { License }\end{array} \begin{array}{l}\text { This article is distributed exclusively by Cold Spring Harbor Laboratory Press for the } \\ \text { first } 12 \text { months after the full-issue publication date (see } \\ \text { http://learnmem.cshlp.org/site/misc/terms.xhtml). After } 12 \text { months, it is available under } \\ \text { a Creative Commons License (Attribution-NonCommercial } 4.0 \text { International), as } \\ \text { described at http://creativecommons.org/licenses/by-nc/4.0/. }\end{array} \\ & \begin{array}{c}\text { Receive free email alerts when new articles cite this article - sign up in the box at the } \\ \text { top right corner of the article or click here. }\end{array} \\ &$\hline\end{aligned}

